\title{
Research Article \\ Effect of Bend Radius on Magnitude and Location of Erosion in S-Bend
}

\author{
Quamrul H. Mazumder, Siwen Zhao, and Kawshik Ahmed \\ Department of Mechanical Engineering, University of Michigan-Flint, 303 East Kearsley Street, Flint, MI 48502, USA \\ Correspondence should be addressed to Quamrul H. Mazumder; qmazumde@umflint.edu
}

Received 28 October 2014; Revised 13 December 2014; Accepted 15 December 2014

Academic Editor: Dimitrios E. Manolakos

Copyright (C) 2015 Quamrul H. Mazumder et al. This is an open access article distributed under the Creative Commons Attribution License, which permits unrestricted use, distribution, and reproduction in any medium, provided the original work is properly cited.

Solid particle erosion is a mechanical process that removes material by the impact of solid particles entrained in the flow. Erosion is a leading cause of failure of oil and gas pipelines and fittings in fluid handling industries. Different approaches have been used to control or minimize damage caused by erosion in particulated gas-solid or liquid-solid flows. S-bend geometry is widely used in different fluid handling equipment that may be susceptible to erosion damage. The results of a computational fluid dynamic (CFD) simulation of diluted gas-solid and liquid-solid flows in an S-bend are presented in this paper. In addition to particle impact velocity, the bend radius may have significant influence on the magnitude and the location of erosion. CFD analysis was performed at three different air velocities $(15.24 \mathrm{~m} / \mathrm{s}-45.72 \mathrm{~m} / \mathrm{s})$ and three different water velocities $(0.1 \mathrm{~m} / \mathrm{s}-10 \mathrm{~m} / \mathrm{s})$ with entrained solid particles. The particle sizes used in the analysis range between 50 and 300 microns. Maximum erosion was observed in water with $10 \mathrm{~m} / \mathrm{s}, 250$ micron particle size, and a ratio of 3.5. The location of maximum erosion was observed in water with $10 \mathrm{~m} / \mathrm{s}, 300$-micron particle size, and a ratio of 3.5. Comparison of CFD results with available literature data showed reasonable and good agreement.

\section{Introduction}

Erosion due to particulated multiphase flow is a complex phenomenon resulting in severe structural damage due to wall thickness loss in high pressure pipelines and fluid handling equipment. Erosive wear damage has been observed in oil and gas pipelines, aircraft, cyclone separators, boilers, fluidized beds, gas turbines, and coal gasification processes. This type of damage was recognized as a leading problem causing pipeline failure [1]. A number of different factors that contribute to erosion include impact velocity, particle size and shape, and mechanical properties of both the target material and the solid particles [2]. Solid particle impact velocity was recognized as the most significant factor influencing erosion by researchers, and the erosion rate is proportional to the exponent of the solid particle velocity or the fluid velocity surrounding the particles [3]. The synergisms of these factors make the erosion process difficult to manage and observe in reality. However, the advancement of computational fluid dynamics (CFD) provides an effective method to predict the flow behavior that can aid in predicting erosion. CFD simulations can provide an economical means of understanding the complex fluid dynamics and how it is influenced by changes in both design and operating conditions [4]. Engineers can obtain real-scale geometry to model a 3D structure under different conditions during CFD analysis. CFD can provide data and valuable visualizations of what will happen in real life when these conditions occur, which will become important reference information applied to the design [5]. CFD models are based on Navier-Stokes equations which include the first principles of mass, momentum, and energy conservation [6]. The most generalized model for multiphase flow is the Eulerian-Eulerian model, based on the principle of interpenetrating continua. It also has ability for continuousdispersed and continuous-continuous systems where each phase is controlled by the Navier-Stokes equations [6].

\section{Background}

Wang and Shirazi investigated the effect of elbows with different radii on erosion and reported that the long radius bend with $r / D>1.5$ (where $r$ is the elbow curvature radius and $D$ is the diameter of pipe) has smaller impingement angles than short radius bend [7]. The study also reported lower erosion when a long radius elbow is used compared to 
a standard elbow $(r / D=1.5)$ for the same flow condition. A mechanistic model was developed by Mazumder et al. to predict erosion in elbows with multiphase flow (gasliquid-solid). The model was based on erosion equations and numerical and experimental results and provides an adequate understanding of the erosion behavior in multiphase annular flow [8].

The solid particle impact angles also have great influence on erosion. For the same material, the erosion caused by an impact angle of $30^{\circ}$ was significantly more than that caused by an impact angle of $90^{\circ}$ [9]. Several investigations used computational methods to predict erosion behavior in different geometries, different solid particles, and different flow velocities and fluids [10-12]. For fluid handling system designers and engineers, identification of the location of maximum erosion is as equally important as the magnitude of the erosion. Most of the available literature data showed studies that identified the magnitude of erosion without specifying the locations. A previous CFD study reported the location of maximum erosion at $182^{\circ}$ from inlet of a U-bend at a $15.24 \mathrm{~m} / \mathrm{s}$ air velocity and 50-micron particle size [13].

Three distinct regions, namely, the core, the layer of peripheral flow, and the region of eddying flow, may be distinguished in a pipe flow. The radius of curvature of bend and Reynolds number are the leading parameters in determining the strength of swirling flow [14]. The flow in multiple bends is more complex than in single bends due to the interaction of the flow dynamics within the two bends. The effect of the bend sweep angle and Reynolds number was studied by Niazmand and Jaghargh [15]. In S-bend or some other multiphase bend, the sweep angles also have a large influence on flow in addition to the diameter used in determining the Reynolds number. The small sweep angle was found to suppress the swirling structure in the second bend while large angles could result in strong vortices in the second bend that can diminish the intensity of vortices in the first bend. Additionally, an adverse pressure gradient always occurs upstream of the first bend outer wall of the S-bend. It occurs at the transition of two bends along the second bend's outer wall and depends on the Reynolds number, sweep angle, and curvature ratio. The effect of the ratio of curvature on erosion in the bend was reported in previous studies $[3,16]$. Although a number of studies were conducted to determine the magnitude and location of erosion in pipes, they were limited to a single velocity and particle size. The location of maximum erosion in a bend at different velocities and particle sizes is extremely important for understanding the erosion behavior in multiphase flow. The maximum mass transfer enhancement was found to increase as the bend radius to diameter ratio $(r / D)$ and decreased due to increase in turbulence levels.

\section{Current Work}

Review of previous work in solid particle erosion was mainly focused on the effect of particle size on magnitude and location of maximum erosion at a constant ratio of bend radius to pipe diameter. The effect of $r / D$ ratio of different bends on erosion was reported in one previous study by
Wang and Shirazi [7]. The current study was conducted to understand the effect of $r / D$ on magnitude and location of erosion in S-bend geometry using CFD. A commercial CFD code FLUENT was used to perform the analysis as presented in the later sections.

\section{Materials and Methods}

4.1. CFD Approach and Analysis. Due to the advanced development of computational resources and capabilities in recent years, the computational fluid dynamics technique has been recognized as a powerful and effective method to predict and analyze erosion behavior. A set of fluid dynamic balance equations, usually in Navier-Stokes formulation for momentum balance, can be solved by CFD codes. The FLUENT [17] code was used in this study which was adopted to solve the balance equation set via domain discretization, using a control volume approach to convert the balance partial differential equations (PDEs) into algebraic equations solved numerically [18].

The equation of motion for a discrete phase dispersed in the continuous phase was solved by a discrete phase model (DPM) option. This option adopts a Lagrangian frame of coordinates and leads to the computation of the particle trajectories. The force balance equation on the particle is solved using the local continuous phase conditions:

$$
\frac{d v_{p}}{d t}=F_{D}\left(v_{f}-v_{p}\right)+g \frac{\left(\rho_{p}-\rho_{f}\right)}{\rho_{p}}+F_{x},
$$

where $v_{p}$ and $v_{f}$ are the particle and fluid velocities, $\rho_{p}$ and $\rho_{f}$ are the particle and fluid densities, respectively, $g$ is the gravitational acceleration, $F_{x}$ is a term accounting for additional forces, and $F_{D}\left(v_{p}-v_{f}\right)$ is the drag force per unit particle mass [1]:

$$
F_{D}=\frac{18 \mu}{\rho_{p} d_{p}^{2}}+\frac{C_{D} R_{e}}{24} .
$$

The solid particle erosion rates at wall boundaries were determined by the following equation:

$$
R_{\text {erosion }}=\sum_{p=1}^{N \text { particles }} \frac{m_{p} C\left(d_{p}\right) f(\alpha) v^{b(v)}}{A_{\text {face }}},
$$

where $C\left(d_{p}\right)$ is a function of particle diameter, $f(\alpha)$ is a function of impact angle, where $\alpha$ is the impact angle of the particle path with the wall face, $v$ is the relative particle velocity, $b(v)$ is a function of relative particle velocity, and $A_{\text {face }}$ is the area of the cell face at the wall. $C, f$, and $b$ are default values, which are $1.8 E-9,1$, and $0 . C, f$, and $b$ are defined as boundary conditions at the wall rather than properties of the material; hence, the default values were not updated to reflect the material being used. Appropriate values of these functions were also specified for solid particles being used and the impacting surface material. The erosion rates were calculated with regard to loss material (area-time) or $\mathrm{kg} / \mathrm{m}^{2}-\mathrm{sec}[1]$. 
TABLE 1: Parameters used in CFD analysis.

\begin{tabular}{lcc}
\hline Type of fluid & Air & Water \\
\hline Fluid density $\left(\mathrm{kg} / \mathrm{m}^{3}\right)$ & 1.225 & 9982 \\
Fluid viscosity $\left(\mathrm{kg} \mathrm{m}^{-1} \mathrm{~s}^{-1}\right)$ & $1.8 \times 10^{-5}$ & 0.001003 \\
CFD element type & \multicolumn{2}{c}{ Tetrahedron } \\
Number of elements & 40,930, \\
Poisson's ratio & 0.30 & \\
Young's modulus $\left(\mathrm{N} \mathrm{m}^{-1}\right)$ & $1 \times 10^{7}$ & \\
& Air: $15.24,30.48$, and $45.72 \mathrm{~m} / \mathrm{s}$ \\
Fluid inlet velocity $(\mathrm{m} / \mathrm{sec})$ & Water: $0.1,1.0$, and $10.0 \mathrm{~m} / \mathrm{sec}$ \\
& $50,100,150,200,250$, and 300 \\
Particle diameter $(\mu \mathrm{m})$ & \multicolumn{2}{c}{ Sand $(1500)$} \\
Particle density $\left(\mathrm{kg} / \mathrm{m}^{3}\right)$ & \multicolumn{2}{c}{1.0} \\
Particle rate $(\mathrm{kg} / \mathrm{sec})$ & $1.5,2.5$, and 3.5 \\
Ratio $(r / D, D=12.7 \mathrm{~mm})$ &
\end{tabular}

4.2. Turbulence Model. Turbulence plays an important role in many chemical engineering processes. The standard $k-\varepsilon$ model is one of the most popular viscosity models based on the Reynolds averaged Navier-Stokes (RANS) equations [19]. The $k-\varepsilon$ model was used in this paper. A realizable $k-\varepsilon$ turbulence model is applied to calculate normal Reynolds stresses and shear Reynolds stresses, and the equation is written as follows [1]:

$$
\begin{aligned}
\frac{\partial(\rho \varepsilon)}{\partial t}+\frac{\partial\left(\rho U_{j} \varepsilon\right)}{\partial x_{j}}= & \frac{\partial}{\partial x_{j}}\left[\left(\mu+\frac{\mu_{t}}{\sigma_{\varepsilon}}\right) \frac{\partial \varepsilon}{\partial x_{j}}\right] \\
& +\rho C_{1} S \varepsilon-\rho C_{\varepsilon 2} \frac{\varepsilon^{2}}{k+\sqrt{(\mu / \rho) \varepsilon}} .
\end{aligned}
$$

The model constants are $C_{\varepsilon 2}=1.9, A_{0}=4.0, \sigma_{k}=1.0$, and $\sigma_{k \varepsilon}=1.2$.

\section{Geometry Detail}

Three S-bends of $12.7 \mathrm{~mm}$ pipe diameter, $r / D=1.5, r / D=$ 2.5 , and $r / D=3.5$, with $50.8 \mathrm{~mm}$ of straight pipe sections upstream and downstream of the bend were used in the CFD analysis. An S-bend geometry with $r / D$ ratio of 1.5 is shown in Figure 1. As the core of the turbulent pipe flow is reasonably uniform, the grid size in this region was relatively coarse. For efficient discretization, the geometry of the fluids flow area was divided into three parts: upstream, downstream, and central parts. The meshed S-bend geometry with $r / D$ ratio of 1.5 is shown in Figure 2. The parameters used in the CFD analysis are presented in Table 1.

\section{Results and Discussion}

CFD analyses were performed for the conditions listed in Table 1 to determine the magnitude and location of maximum erosion wear damage of the S-bend. As Figure 2 showed, the bend closer to the inlet was defined as bend 1 and the bend closer to the outlet was defined as bend 2. The location of maximum erosion is shown as angles measured from the start of the bend.

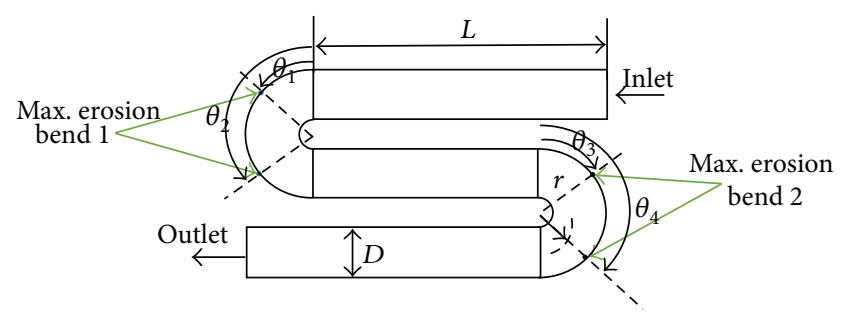

FIGURE 1: S-bend geometry with $r / D=1.5$.

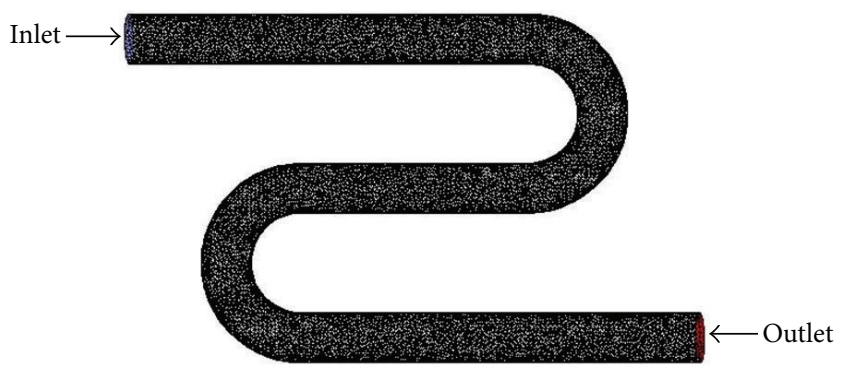

Figure 2: Meshed geometry with flow direction.

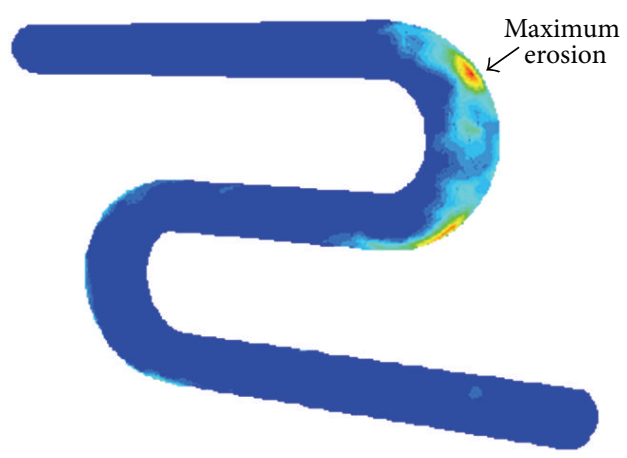

FIgURe 3: Maximum erosion in S-bend with $r / D=1.5$.

A CFD result of erosion at $15.24 \mathrm{~m} / \mathrm{s}$ air velocity, 50micron particle size, and the ratio of 1.5 was shown in Figure 3. Erosion was observed in both bend 1 and bend 2 . Furthermore, erosion was observed in two locations in bend 1 and two locations in bend 2. The location of maximum erosion for this condition was 34.8 and 157 degrees in bend 1 and 46.5 and 150.1 degrees in bend 2 .

The effect of air velocities and particle sizes on erosion with $r / D=1.5$ is presented in Figures $4(\mathrm{a})$ and $4(\mathrm{~b})$. Maximum erosion was observed at $15.24 \mathrm{~m} / \mathrm{sec}$ at $20-73$ degrees, with 100-micron particles. No significant differences in erosion were observed for particle sizes between 150 and 300 microns. Large amounts of erosion were observed in both bends for some conditions. For example, with 200-micron particle size, maximum erosions were observed at 25 degrees in bend 1 and at 44.2 degrees in bend 2 .

The effect of air velocities and particle sizes on an erosion of ratio 2.5 is presented in Figures 4(c) and 4(d). Erosions were observed in one location of the bend compared to multiple locations observed in the bend with $r / D=1.5$ for all velocities and particle sizes. This validates the literature 


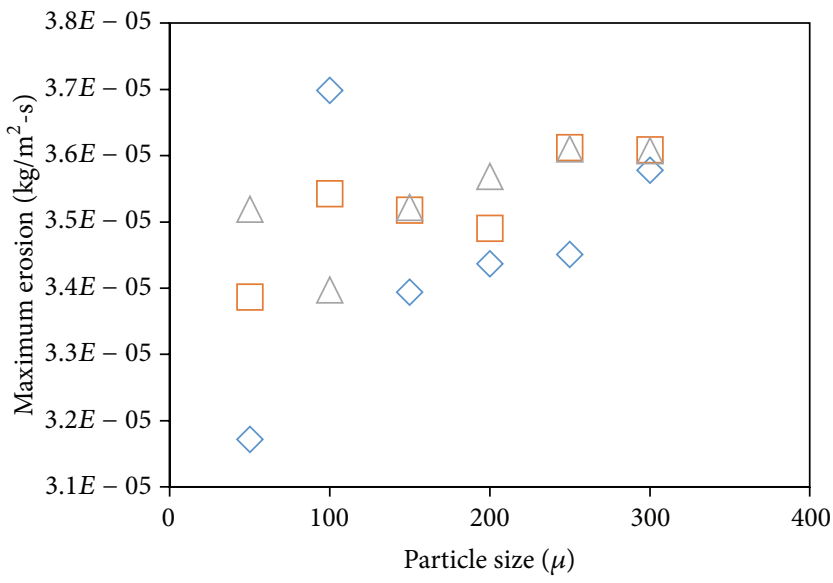

(a)

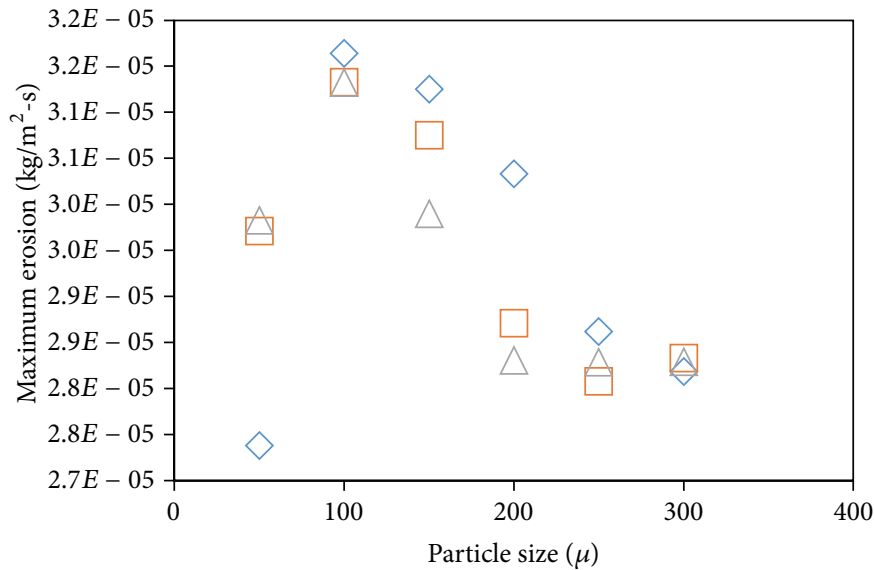

(c)

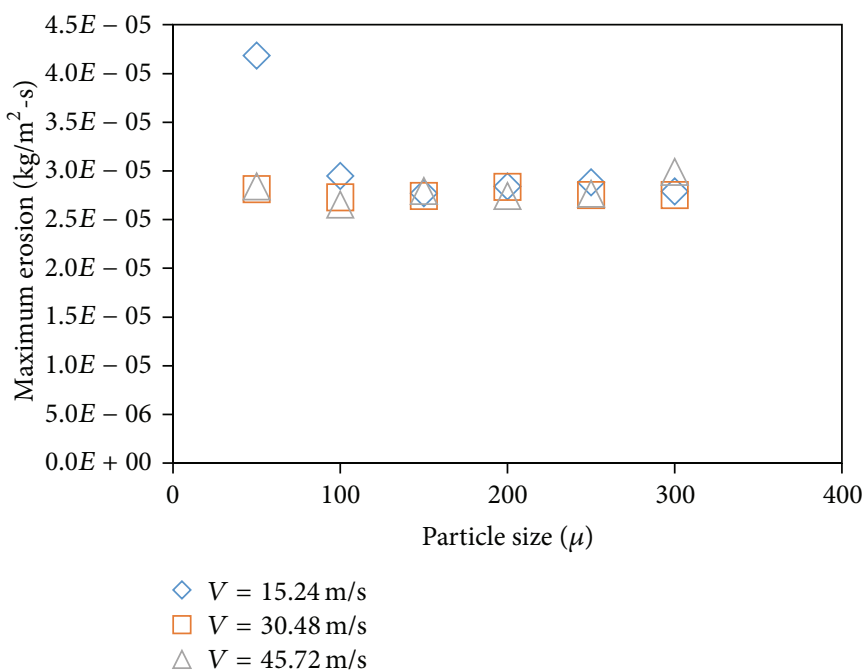

(e)

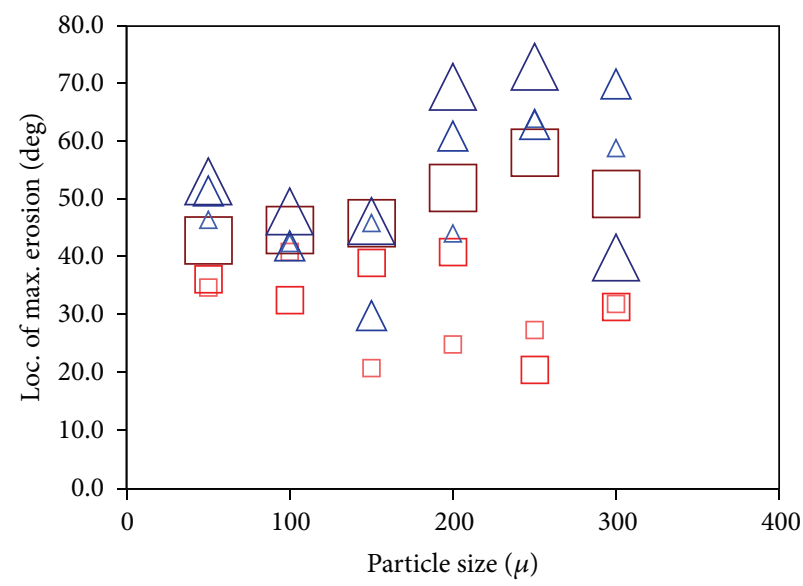

(b)

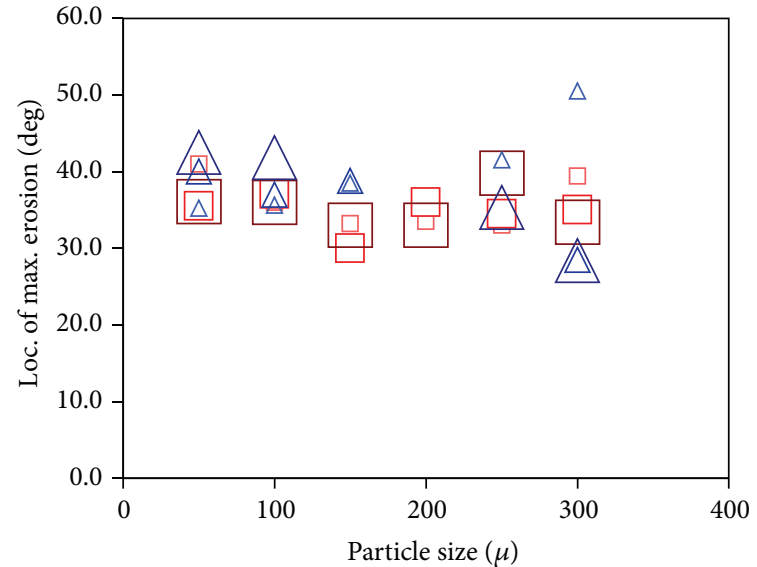

(d)

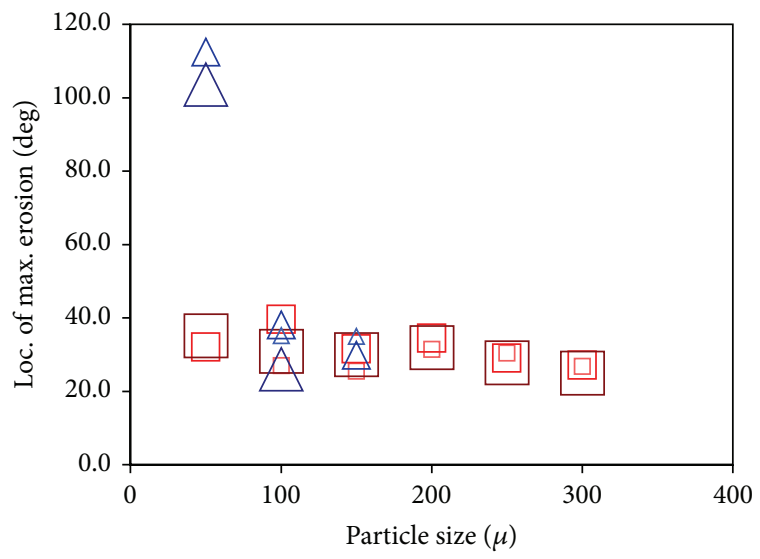

$\square V=15.24 \mathrm{~m} / \mathrm{s}$ bend $1 \quad \square V=30.48 \mathrm{~m} / \mathrm{s}$ bend 1

$\square V=45.72 \mathrm{~m} / \mathrm{s}$ bend $1 \quad \Delta V=15.24 \mathrm{~m} / \mathrm{s}$ bend 2

$\triangle V=30.48 \mathrm{~m} / \mathrm{s}$ bend $2 \Delta V=45.72 \mathrm{~m} / \mathrm{s}$ bend 2

(f)

Figure 4: (a) Effect of air velocity on erosion $(r / D=1.5)$. (b) Location of erosion with air velocities $(r / D=1.5)$. (c) Effect of air velocity on erosion $(r / D=2.5)$. (d) Location of erosion at air velocities $(r / D=2.5)$. (e) Effect of air velocity on erosion $(r / D=3.5)$. (f) Location of erosion with air velocities $(r / D=3.5)$. 
TABLE 2: Comparison of available literature data.

\begin{tabular}{|c|c|c|c|c|}
\hline Ref./geometry & Fluid/particle size & Fluid velocity & Amount of erosion & Location of max. erosion \\
\hline \multirow{2}{*}{$\begin{array}{l}\text { Mazumder } 2012 \text { [13]: CFD } \\
\text { (U-bend) }\end{array}$} & Air (50-300 microns) & $15.24 \mathrm{~m} / \mathrm{s}, 30.48 \mathrm{~m} / \mathrm{s}$, and $45.72 \mathrm{~m} / \mathrm{s}$ & N/A & $40^{\circ}-182^{\circ}$ \\
\hline & Water (50-300 microns) & $15.24 \mathrm{~m} / \mathrm{s}, 30.48 \mathrm{~m} / \mathrm{s}$, and $45.72 \mathrm{~m} / \mathrm{s}$ & $\mathrm{N} / \mathrm{A}$ & $60^{\circ}-155^{\circ}$ \\
\hline $\begin{array}{l}\text { Wang and Shirazi } 2003 \text { [7]: } \\
\text { CFD (elbow) }\end{array}$ & Air (100-350 microns) & $50 \mathrm{~m} / \mathrm{s}$ & $\mathrm{N} / \mathrm{A}$ & $30^{\circ}-40^{\circ}$ \\
\hline $\begin{array}{l}\text { Suhane and Agarwal } 2012 \\
\text { [20]: experiment }\end{array}$ & Air (106-125 microns) & $18.23 \mathrm{~m} / \mathrm{s}$ & Mass loss $99.6 \mathrm{~g}$ & $24^{\circ}-32^{\circ}$ \\
\hline \multirow{2}{*}{$\begin{array}{l}\text { Mills and Mason } 1977 \text { [21]: } \\
\text { experiment (elbow) }\end{array}$} & \multirow{2}{*}{ Air (70 and 230 microns) } & $26 \mathrm{~m} / \mathrm{s}$ & $44 \mathrm{~g}$ mass loss & \multirow{2}{*}{$32^{\circ}, 38^{\circ}$} \\
\hline & & $32 \mathrm{~m} / \mathrm{s}$ & $115 \mathrm{~g}$ mass loss & \\
\hline $\begin{array}{l}\text { Fan et al. } 2001[10] \text { : } \\
\text { experiment (elbow) }\end{array}$ & Gas & $41.2 \mathrm{~m} / \mathrm{s}$ & N/A & $20^{\circ}-30^{\circ}$ \\
\hline \multirow{2}{*}{$\begin{array}{l}\text { El-Behery et al. } 2010 \text { [22]: } \\
\text { CFD (curved duct) }\end{array}$} & \multirow{2}{*}{ Gas (100 microns) } & \multirow{2}{*}{$10 \mathrm{~m} / \mathrm{s}, 20 \mathrm{~m} / \mathrm{s}$, and $30 \mathrm{~m} / \mathrm{s}$} & $\mathrm{N} / \mathrm{A}$ & $15^{\circ}-70^{\circ}$ \\
\hline & & & $\mathrm{N} / \mathrm{A}$ & $10^{\circ}-140^{\circ}$ \\
\hline
\end{tabular}

TABLE 3: Results of CFD and experimental investigations.

\begin{tabular}{|c|c|c|c|c|}
\hline Ref./geometry & Fluid/particle size & Fluid velocity & Amount of erosion & $\begin{array}{c}\text { Location of max. } \\
\text { erosion }\end{array}$ \\
\hline \multirow[t]{2}{*}{$\begin{array}{l}\text { Mazumder [current work]: } \\
\text { CFD (S-bend) }\end{array}$} & Air (300 microns) & $\begin{array}{c}15.24 \mathrm{~m} / \mathrm{s} \text {, } \\
30.48 \mathrm{~m} / \mathrm{s} \text {, and } \\
45.72 \mathrm{~m} / \mathrm{s}\end{array}$ & $\begin{array}{l}3.57 E-5 \\
3.61 E-5 \\
3.61 E-5\end{array}$ & $\begin{array}{l}32^{\circ}, 153^{\circ} \\
32^{\circ}, 151^{\circ} \\
41^{\circ}, 147^{\circ}\end{array}$ \\
\hline & Air (150 microns) & $\begin{array}{c}15.24 \mathrm{~m} / \mathrm{s} \text {, } \\
30.48 \mathrm{~m} / \mathrm{s} \text {, and } \\
45.72 \mathrm{~m} / \mathrm{s}\end{array}$ & $\begin{array}{l}3.39 E-5 \\
3.52 E-5 \\
3.52 E-5\end{array}$ & $\begin{array}{l}21^{\circ}, 148^{\circ} \\
39^{\circ}, 151^{\circ} \\
46^{\circ}, 142^{\circ}\end{array}$ \\
\hline \multirow[t]{2}{*}{$\begin{array}{l}\text { Mazumder [current work]: } \\
\text { experiment (S-bend) }\end{array}$} & Air (300 microns) & $\begin{array}{c}15.24 \mathrm{~m} / \mathrm{s} \text {, } \\
30.48 \mathrm{~m} / \mathrm{s} \text {, and } \\
45.72 \mathrm{~m} / \mathrm{s}\end{array}$ & $\mathrm{N} / \mathrm{A}$ & $\begin{array}{l}27^{\circ} \\
32^{\circ} \\
44^{\circ}\end{array}$ \\
\hline & Air (150 microns) & $\begin{array}{c}15.24 \mathrm{~m} / \mathrm{s} \text {, } \\
30.48 \mathrm{~m} / \mathrm{s} \text {, and } \\
45.72 \mathrm{~m} / \mathrm{s}\end{array}$ & N/A & $\begin{array}{r}27^{\circ} \\
42.5^{\circ} \\
41^{\circ}\end{array}$ \\
\hline
\end{tabular}

reported data indicating a reduction of erosion by using a larger radius elbow geometry. The effect of air velocities and particle sizes on erosion of ratio 3.5 is presented in Figures 4(e) and 4(f). The magnitude and location of erosions were somewhat similar to the previous bend with $r / D=2.5$.

The effect of water velocities and particle sizes on magnitude and locations of maximum erosion with $r / D=1.5$ is presented in Figures 5(a) and 5(b). Maximum erosion was observed at 105.5 degrees with $0.1 \mathrm{~m} / \mathrm{s}$ air velocity and 50 micron sand size. Erosion at $0.1 \mathrm{~m} / \mathrm{sec}$ was 3 times more than erosion at $1 \mathrm{~m} / \mathrm{sec}$ and 8 times more than at $10 \mathrm{~m} / \mathrm{sec}$. Location of erosion for water was further downstream of the radius of the bend compared to air. For example, location of maximum erosion with water was 105.5 degrees compared to 20-73 degrees with air.

The effect of water velocities and particle sizes on magnitude and location of erosion with $r / D$ ratio of 2.5 is presented in Figures 5(c) and 5(d). Maximum erosion was at $0.1 \mathrm{~m} / \mathrm{s}$ with 50 -micron sand size which is 2.6 times higher than at $1 \mathrm{~m} / \mathrm{sec}$ and 10 times higher than at $10 \mathrm{~m} / \mathrm{s}$. No significant difference in erosion was observed with water velocities of $1 \mathrm{~m} / \mathrm{sec}$ and $10 \mathrm{~m} / \mathrm{sec}$.

The effect of water velocity and particle size on maximum erosion with $r / D$ ratio of 3.5 is shown in Figures 5(e) and 5(f). Maximum erosion was observed at 106-120 degrees with $0.1 \mathrm{~m} / \mathrm{s}$ and 250 -micron particles. The maximum erosion at $0.1 \mathrm{~m} / \mathrm{sec}$ was 4.3 times higher than that at $1 \mathrm{~m} / \mathrm{s}$ and 5.9 times higher than that at $10 \mathrm{~m} / \mathrm{s}$. No erosion was observed in bend 1 at $10 \mathrm{~m} / \mathrm{s}$ for 200 and 250 microns.

A comparison of literature reported erosion results is presented in Table 2. Due to limited availability of erosion results for S-bend geometry, data presented in Table 2 are for different types of bends including elbows, U-bends, and ducts. Mazumder [13] investigated the location of maximum erosion in U-bends with three different air and water velocities. Maximum erosion was observed at 182 degrees from inlet at $15.24 \mathrm{~m} / \mathrm{sec}$ with 300 -micron particle size. Suhane and Agarwal [20] reported experimental results of erosion in 51 and $102 \mathrm{~mm}$ diameter bends in a 40-meter-long test loop. At $18.23 \mathrm{~m} / \mathrm{sec}$ air velocity maximum mass loss was 99.6 grams in the $51 \mathrm{~mm}$ bend at a 24-degree impact angle.

The results of current CFD and experimental investigations are presented in Table 3 . The experimental results showed a good agreement with CFD results. For example, at $45.72 \mathrm{~m} / \mathrm{s}$ air velocity with 300 microns, CFD results showed the location of maximum erosion was $41^{\circ}$ and $147.2^{\circ}$ in bend 1 . For the above condition, experimental results showed location of maximum erosion at 44 degrees. 


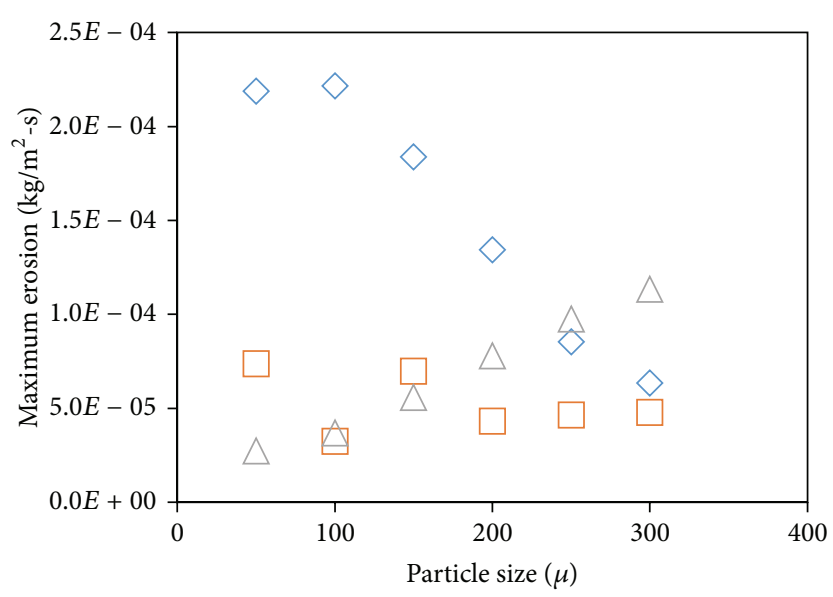

(a)

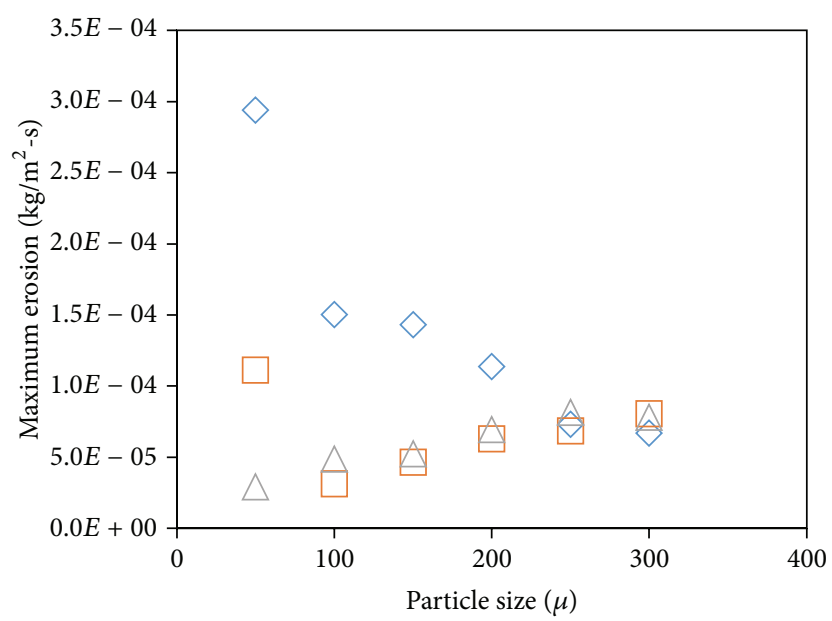

(c)

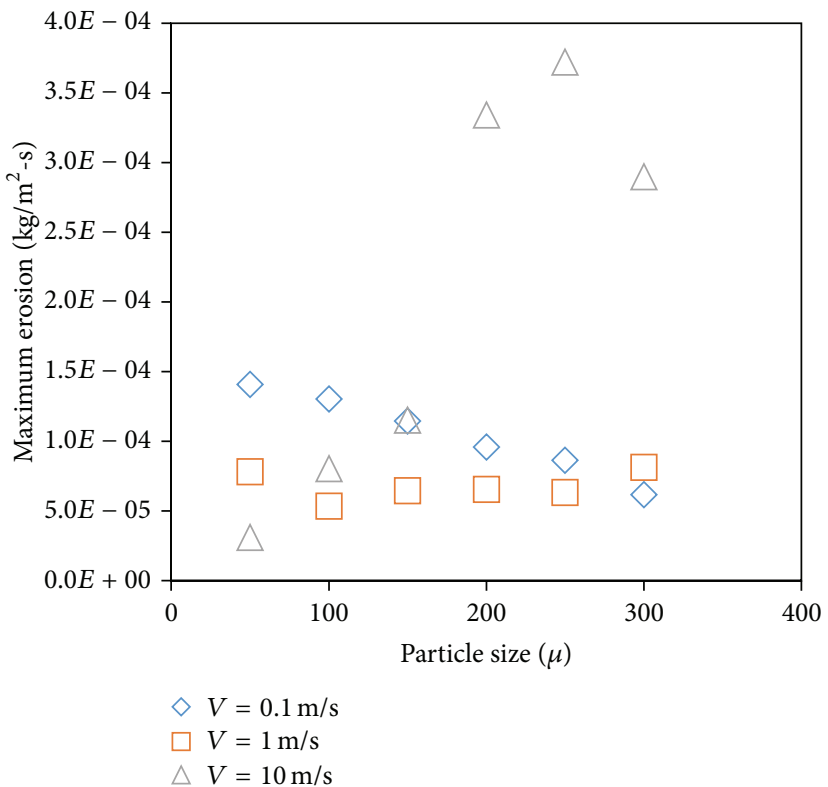

(e)

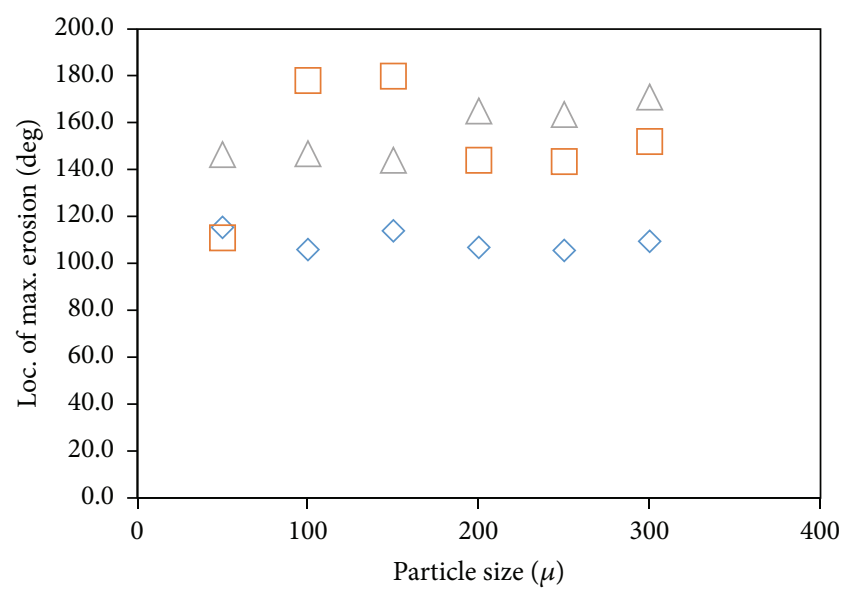

(b)

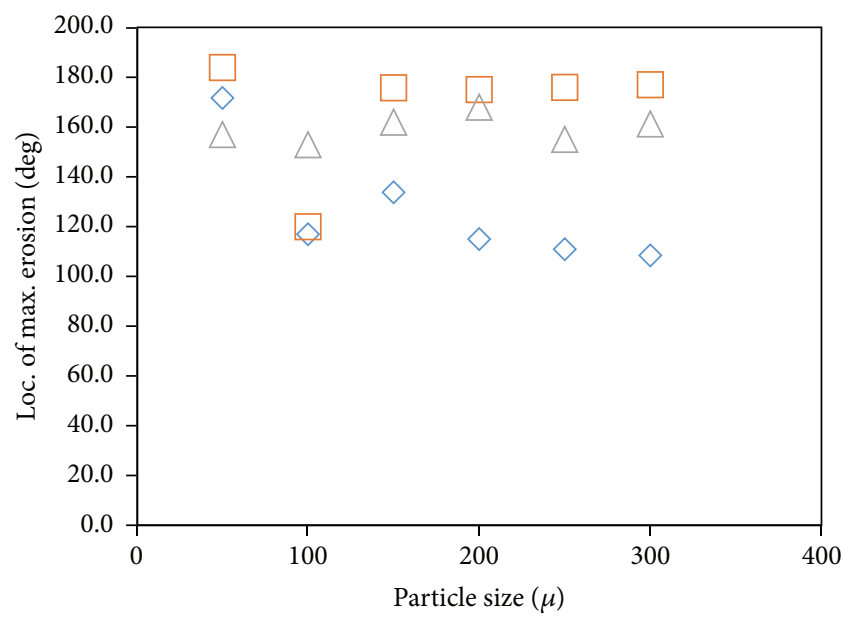

(d)

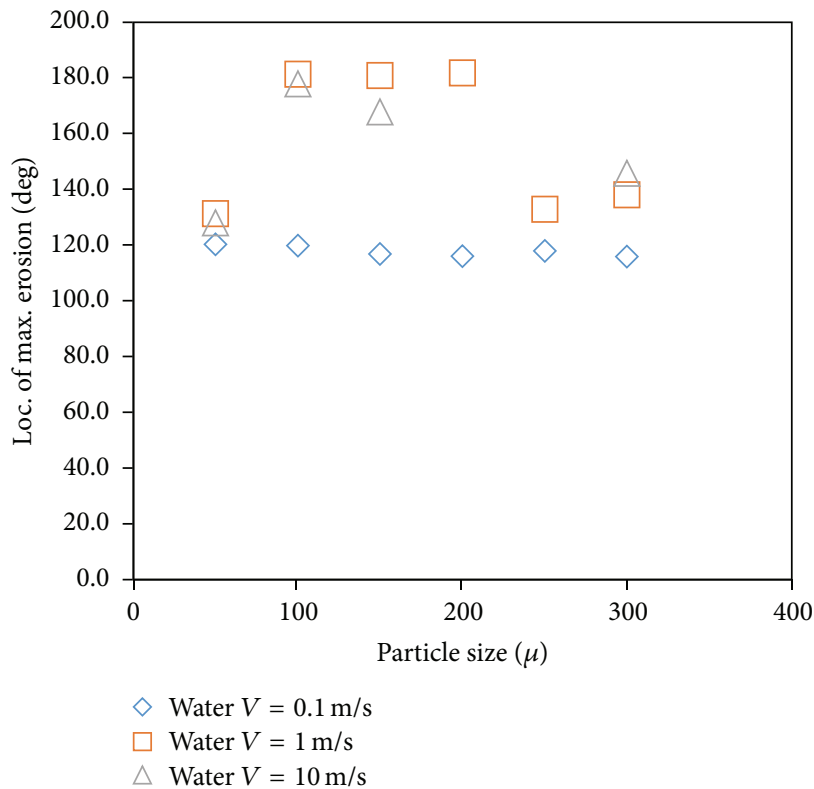

(f)

Figure 5: (a) Effect of water velocity on erosion $(r / D=1.5)$. (b) Location of erosion with water velocities $(r / D=1.5)$. (c) Effect of water velocity on erosion $(r / D=2.5)$. (d) Location of erosion with water velocities $(r / D=2.5)$. (e) Effect of water velocity on erosion $(r / D=3.5)$. (f) Location of erosion with water velocities $(r / D=3.5)$. 


\section{Conclusions}

CFD-based erosion prediction for S-bend geometry of 12.7millimeter diameter with three different $r / D(1.5,2.5$, and 3.5) is presented in this paper. CFD simulations were performed using a comprehensive procedure that included flow simulation, particle tracking, and erosion calculation. Three different air and water velocities with six different particle sizes ranging from 50 to 300 microns were used in the simulation. Experimental investigations were conducted with an S-bend with $r / D=1.5$ and for three different air velocities of 15.24, 30.48 , and $45.72 \mathrm{~m} / \mathrm{sec}$ with two different particle sizes of 150 and 300 microns. The CFD and experimental results were compared with available literature results showing reasonably good agreements. CFD simulation results presented in this paper will shed some light on the importance of location of maximum erosion in S-bend geometry. The study presented in this paper will provide better understanding of the relative magnitude and location of erosion in S-bend geometry.

\section{Conflict of Interests}

The authors declare that there is no conflict of interests regarding the publication of this paper.

\section{Acknowledgments}

The authors would like to thank the Office of Research at the University of Michigan-Flint for financial support. The work presented was supported by Research Grant no. U042784. Kawshik Ahmed also provided support in the CFD analysis presented in the paper.

\section{References}

[1] Q. H. Mazumder, "Effect of particle size on magnitude and location of maximum erosion in S-bend," in Proceedings of the ASME 2014 Fluids Engineering Summer Meeting (FEDSM '14), FEDSM2014-2127, Chicago, Ill, USA, August 2014.

[2] Q. Chen and D. Y. Li, "Computer simulation of solid particle erosion," Wear, vol. 254, no. 3-4, pp. 203-210, 2003.

[3] I. Dorina, "Reduction of pipe wall erosion by creating a vortex flow in anthracite powder pneumatic transport for power plants," in Proceedings of the International Conference on Renewable Energies and Power Quality, European Association for the Development of Renewable Energies, Environment and Power Quality, March 2012.

[4] S. Bernardo, M. Mori, A. P. Peres, and R. P. Dionísio, "3-D computational fluid dynamics for gas and gas-particle flows in a cyclone with different inlet section angles," Powder Technology, vol. 162, no. 3, pp. 190-200, 2006.

[5] C. Knatz, "Modeling with CFD," Public Works, vol. 136, no. 3, pp. 50-55, 2005.

[6] A. Sharifi and A. Mohebbi, "A combined CFD modeling with population balance equation to predict pressure drop in venturi scrubbers," Research on Chemical Intermediates, vol. 40, no. 3, pp. 1021-1042, 2014.

[7] J. Wang and S. A. Shirazi, "A CFD based correlation for erosion factor for long-radius elbows and bends," Journal of Energy
Resources Technology, Transactions of the ASME, vol. 125, no. 1, pp. 26-34, 2003.

[8] Q. H. Mazumder, S. A. Shirazi, and B. S. McLaury, "Prediction of solid particle erosive wear of elbows in multiphase annular flow-model development and experimental validation," Journal of Energy Resources Technology, vol. 130, no. 2, Article ID 023001, 10 pages, 2008.

[9] Q. Chen and D. Y. Li, "Computer simulation of solid particle erosion," Wear, vol. 254, no. 3-4, pp. 203-210, 2003.

[10] J. Fan, J. Yao, X. Zhang, and K. Cen, "Experimental and numerical investigation of a new method for protecting bends from erosion in gas-particle flows," Wear, vol. 251, no. 1, pp. 853860, 2001.

[11] I. Finnie, "Erosion of surfaces by solid particles," Wear, vol. 3, no. 2, pp. 87-103, 1960.

[12] P. Rudolfa and M. Desováa, "Flow characteristics of curved ducts," Applied and Computational Mechanica, vol. 1, pp. 255264, 2007.

[13] Q. H. Mazumder, "Effect of liquid and gas velocities on magnitude and location of maximum erosion in U-bend," Open Journal of Fluid Dynamics, vol. 2, no. 2, pp. 29-34, 2012.

[14] J. R. Weske, Experimental Investigation of Velocity Distributions Downstream of Single Dust Bends, No. NACA-TN-1471, National Aeronautics and Space Administration, Washington, DC, USA, 1948.

[15] H. Niazmand and E. R. Jaghargh, "Bend sweep angle and reynolds number effects on hemodynamics of S-shaped arteries," Annals of Biomedical Engineering, vol. 38, no. 9, pp. 28172828, 2010.

[16] K. Sudo, M. Sumida, and H. Hibara, "Experimental investigation on turbulent flow in a circular-sectioned 90-degree bend," Experiments in Fluids, vol. 25, no. 1, pp. 42-49, 1998.

[17] I. Fluent, "Fluent 14.5 user guide," Tech. Rep. NH-03766, Fluent Inc., 2002.

[18] B. Bozzini, M. E. Ricotti, M. Boniardi, and C. Mele, "Evaluation of erosion-corrosion in multiphase flow via CFD and experimental analysis," Wear, vol. 255, no. 1-6, pp. 237-245, 2003.

[19] D. Kuzmin, O. Mierka, and S. Turek, "On the implementation of the $\kappa-\varepsilon$ turbulence model in incompressible flow solvers based on a finite element discretisation," International Journal of Computing Science and Mathematics, vol. 1, no. 2-4, pp. 193206, 2007.

[20] A. Suhane and V. K. Agarwal, "Effect of bend geometry on erosion and product degradation in pneumatic conveying pipeline systems," International Journal of Engineering Research and Applications, vol. 2, no. 4, pp. 129-136, 2012.

[21] D. Mills and J. S. Mason, "Particle size effects in bend erosion," Wear, vol. 44, no. 2, pp. 311-328, 1977.

[22] S. M. El-Behery, M. H. Hamed, K. A. Ibrahim, and M. A. El-Kadi, "CFD evaluation of solid particles erosion in curved ducts," Journal of Fluids Engineering, vol. 132, no. 7, Article ID 071303, 2010. 

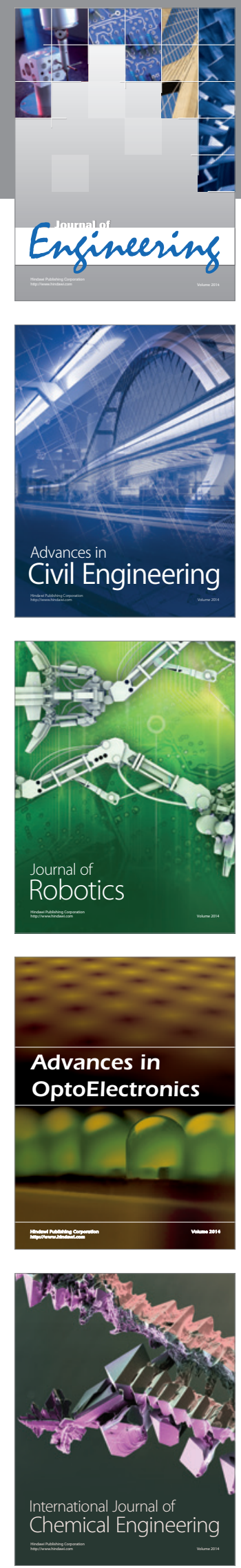

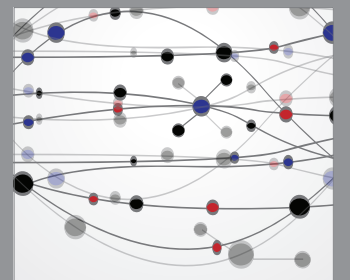

The Scientific World Journal
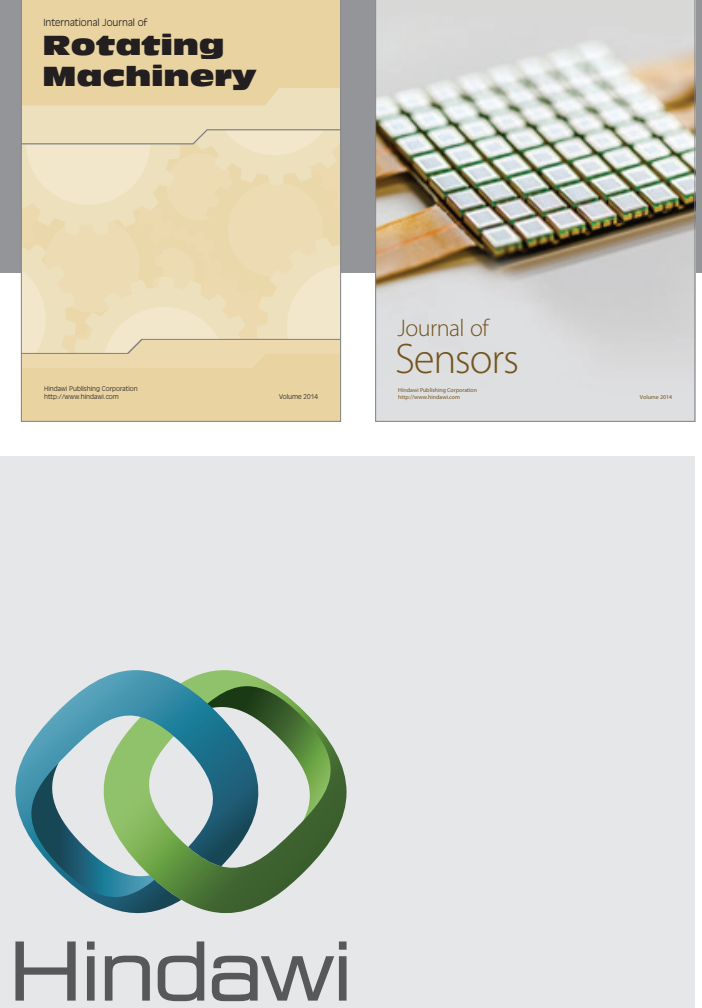

Submit your manuscripts at http://www.hindawi.com
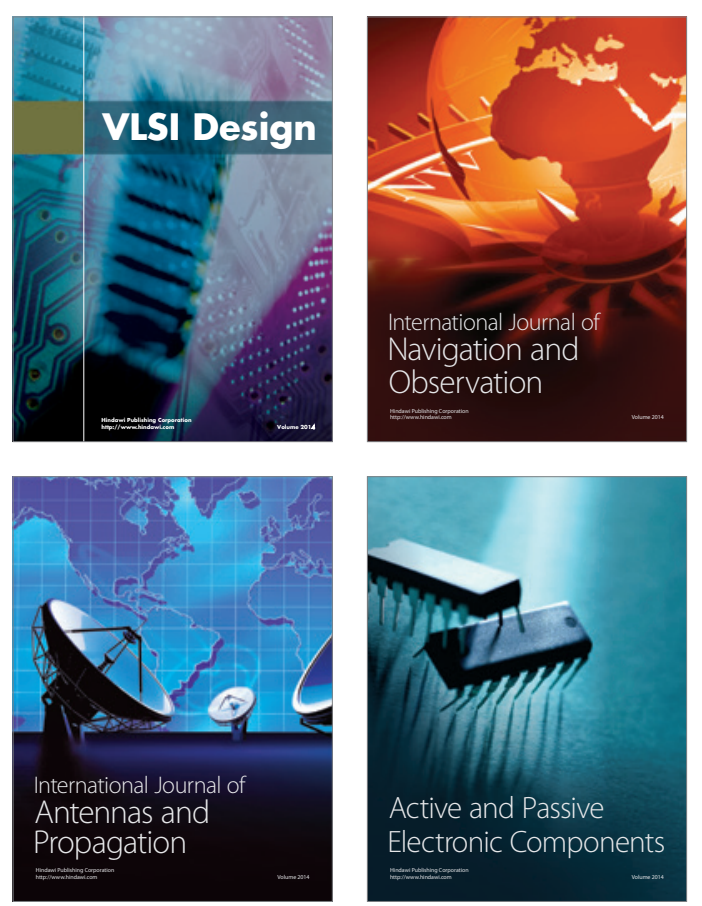
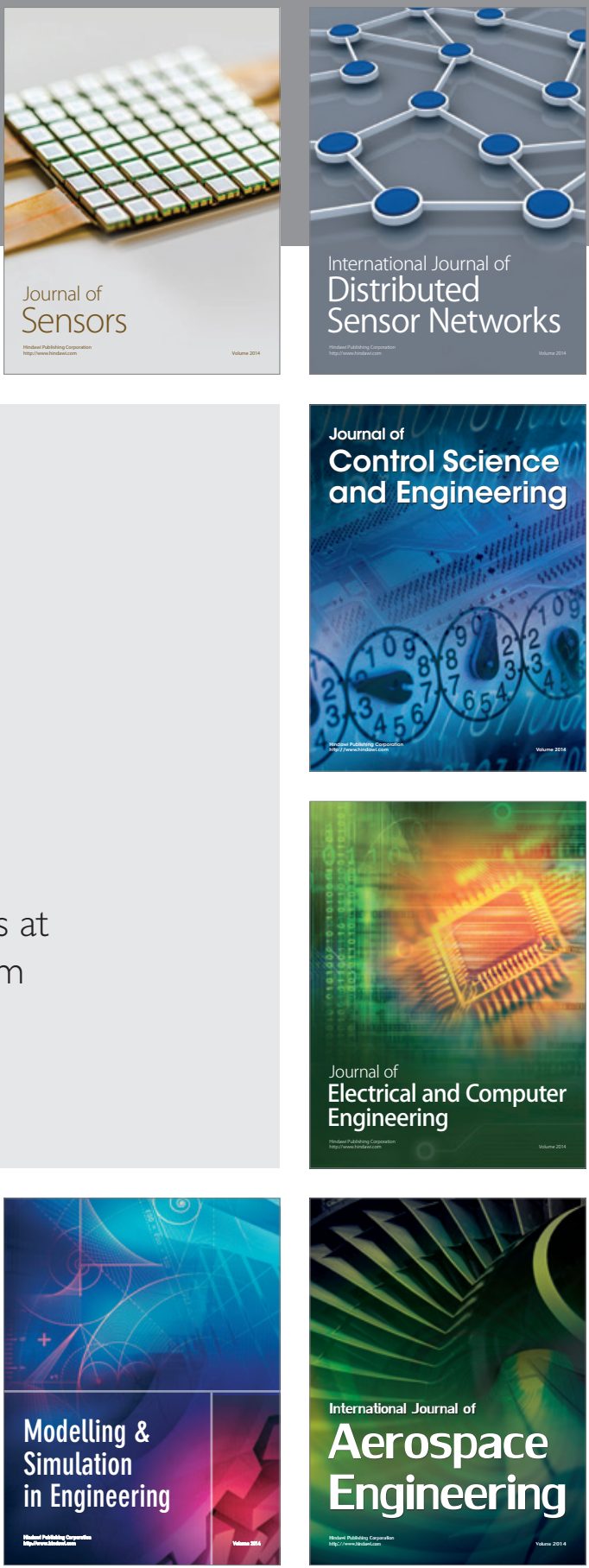

Journal of

Control Science

and Engineering
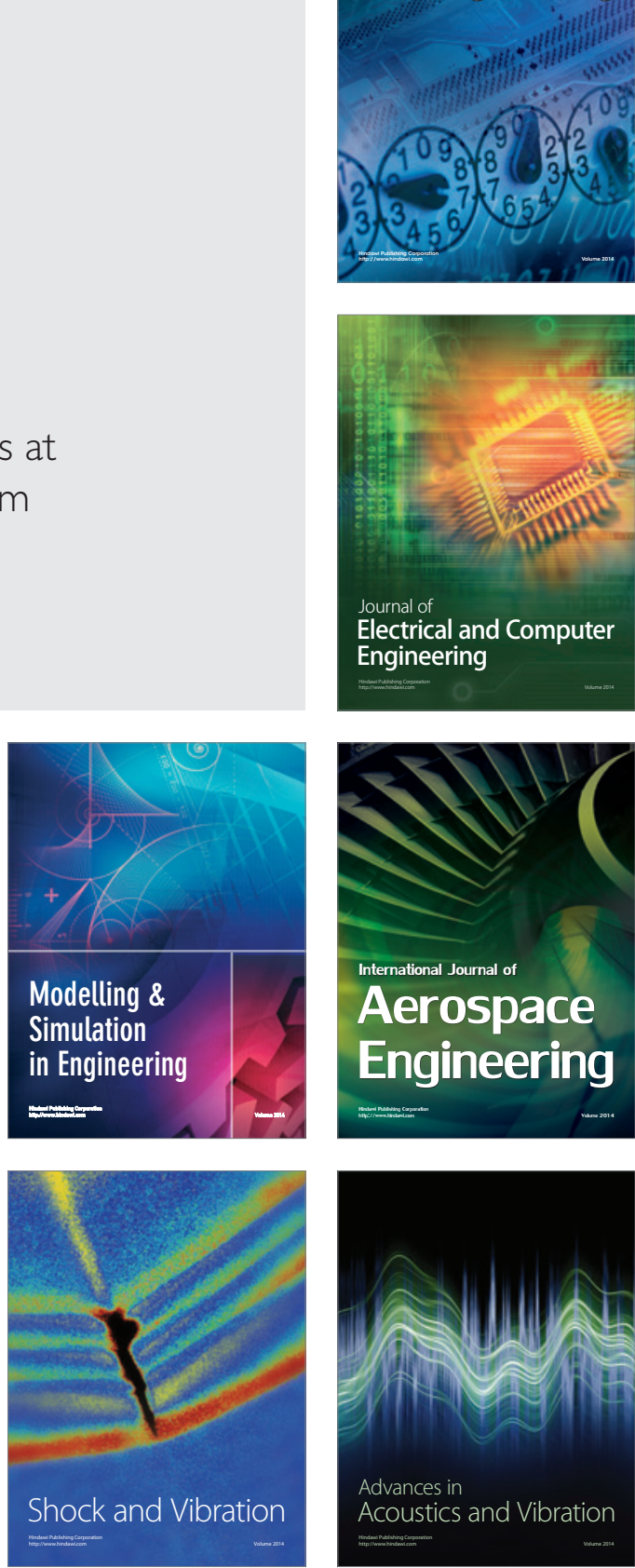